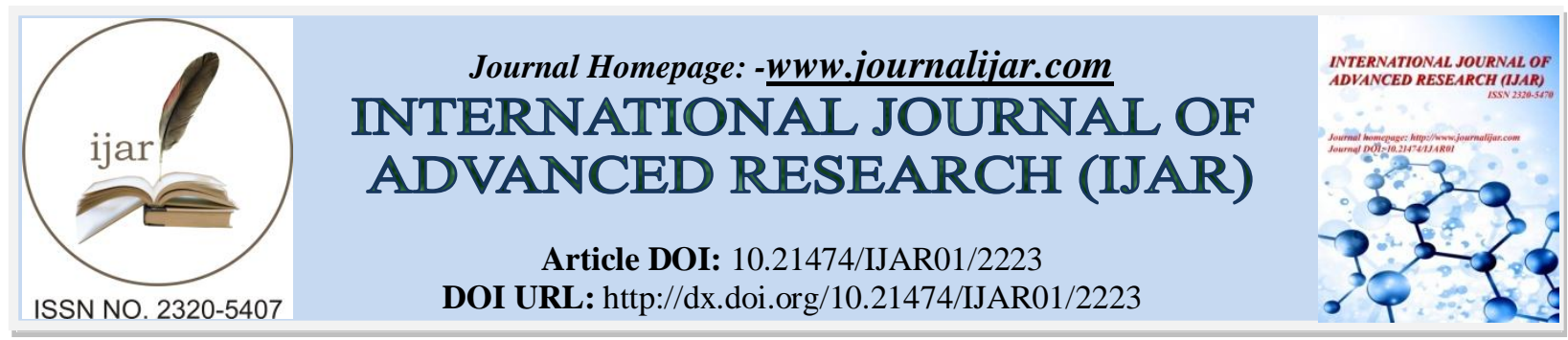

RESEARCH ARTICLE

\title{
END OF LIFE CARE FOR HAEMATOLOGIC MALIGNANCIES: A RETROSPECTIVE COHORT STUDY FROM THE STATE OF QATAR.
}

\author{
*Azza Hassan MD ${ }^{1,2,3}$, Shereen Elazzazy, BSc Pharm PharmD ${ }^{1}$ and Pascale Haddad ${ }^{2}$. \\ 1. National Center for Cancer Care and Research, Hamad Medical Corporation, Doha, Qatar. \\ 2. Weill Cornell Medical College in Qatar, Doha, Qatar. \\ 3. Cancer Management \& Research, Medical Research Institute, Alexandria University, Egypt.
}

\section{Manuscript Info}

\section{Manuscript History}

Received: 28 September 2016

Final Accepted: 30 October 2016

Published: November 2016

\section{Abstract}

Copy Right, IJAR, 2016,. All rights reserved.

\section{Introduction}

Aggressiveness of care at End of Life (EOL) has recently emerged as an important indicator of quality of care in most oncology centers ${ }^{(8,14,3)}$.The definition of indicators for aggressiveness of care for oncology patients has been clearly stated through the work of Earle et al in $2003^{(11)}$. It includes one or more of the following: receiving any chemotherapy regimen in the last 14 days of life, receiving a new chemotherapy regimen in the last 30 days of life, more than one Emergency Department (ED) visit within 30 days of death, more than one hospital admission or spending more than 14 days in hospital in the last month of life, an Intensive Care Unit (ICU) admission in the last month of life or death in an acute care hospital ${ }^{(\mathbf{9 , 1 0 , 4 , 2 2})}$. The accepted International overall percentage of aggressive care at EOL for patients with solid tumors lies between $20 \%-25 \%^{(22,7,1)}$. However, this percentage is not always met and some centers report much higher percentage due to variable factors. Those percentages can reach up to $50 \%$ in countries such as Korea ${ }^{(19)}$ and $70 \%$ in Qatar ${ }^{(3)}$.

Few studies have addressed EOL care among patients with haematologic malignancies ${ }^{(17)}$. There has been an assumption that patients with haematologicmalignancies are exposed to a higher percentage of aggressive care near EOL, compared to solid tumors. This has been mainly attributed to the fact that patients with haematologic malignancies have usually chemosensitive tumors and more options for second and third line combination chemotherapy treatments aiming to control the progressive disease ${ }^{(\mathbf{1 7}, \mathbf{1 2}, \mathbf{2 0}, \mathbf{1 6})}$.In addition to that, patients with haematologic malignancies present with complications such as severe bacterial infections, septicemia, and bleeding problems that necessitate ICU admission ${ }^{(21,6,13)}$. The aim of the present study is to report on the quality of EOL care for patients with hematologic malignancies treated at the National Center for Cancer Care \& Research (NCCCR), the only tertiary care cancer center in Qatar. The study also aims to compare the quality of EOL care between patients with hematologic malignancies and those with solid tumors treated in the same period of time at NCCCR.

\section{Materials and Methods:-}

All deaths between 1-1-2009 till 31-12-2013 in which hematologic malignancy was the underlying cause were extracted from the National Registry of Deaths database. Those were compared to deaths over the same period of 
time for patients who died from solid tumors. The underlying cause of death was recorded in the database using the International Classification of Diseases, Tenth revision, codes.

A retrospective chart review was conducted to measure for markers of Aggressive EOL cancer care, defined as occurrence of one or more of the following indicators: receiving any chemotherapy regimen in the last 14 days of life, receiving a new chemotherapy regimen in the last 30 days of life, more than one Emergency Department (ED) visit within 30 days before death, ICU admission in the last 30 days of life, more than one hospital admission or spending more than 14 days in the hospital in the last month of life, or death in an acute care hospital.

Variables studied included age at death, gender, Nationality (Qatari vs others), primary tumor site (hematologic vs solid tumors) and place of death (Palliative care unit, Oncology unit, Hamad General Hospital, ICU, ED, brought in dead or others). We then compared between solid tumors and hematologic malignancies for each of the indicators that were used to measure aggressiveness of care at EOL.

Analysis:- We used an $\mathrm{X}^{2}$ test to test for differences between the 2 groups where $\mathrm{P}<0.05$ was considered statistically significant.

For the cohort of patients which constituted the basis of that study (hematologic malignancies), we used the Cochrane-Armitage test to evaluate the time trends in aggressiveness of care at EOL for each year separately from 2009 till 2013. All statistical analyses were conducted using STATA software version 13 (STATA, College station, Tx, Computing Resource Center, Santa Monica, CA).

Ethics:- The study was approved by the Research Ethics Committee, Hamad Medical Corporation, Medical Research Center, Qatar.

\section{Results:-}

A total of 97 patients with hematologic malignancies constituted the cohort of this study. This constituted $12 \%$ of the total number of cases with any cancer diagnosis who were reported dead over the 5 years period from 20092013. Males were more common than females (67 patients versus 30 patients respectively) with a Male to Female ratio of 2.23: 1 .

Patients with hematologic malignancies were significantly younger than those with solid tumors (Median age 48 years versus 60 years, $p<0.001$ ). Significantly more female patients were reported in the solid tumor group compared to those in the hematologic malignancy group (48\% vs $31 \%$ with a pvalue of 0.001 ). All patients' characteristics are shown in Table 1.

Patients with hematologic malignancies had significantly more ER visits in the last month of life compared to those with solid tumors $(68 \%$ versus $56 \%$ with a $p$ value $<0.001)$. They also had significantly higher ICU admissions compared to solid tumors $(57 \%$ versus $29 \% p<0.001$ ). They were also more likely to receive chemotherapy in the last 14 days of life compared to patients with solid tumors $(11 \%$ versus $6 \%, \mathrm{p}=0.033)$. Patients with hematologic malignancies were also less likely to be referred to palliative care compared to those with solid tumors (9\% versus $31 \%)$. This difference was statistically significant with a $p$ value $<0.001$.

There were no other significant differences between the 2 groups in terms of the remaining indicators for aggressiveness of care at EOL as shown in Table 2. There was a statistically significant decrease in the overall proportion of aggressiveness of care (at least one measure) from $89 \%$ in 2009 to $50 \%$ in 2013 ( $\mathrm{p}=0.05$ ), as shown in Table 3.

The composite measure of aggressiveness (0-5 measures maximum) also decreased from 1.74 in 2009 to 0.67 in 2013. However this difference did not reach statistical significance $(\mathrm{p}=0.09)$ as shown in Table 3.

The variable measures of care administered near the end of life during the 5-year study period are shown in Table 4. The only statistically significant factor that showed decline along the years was the average number of ED visits in the last month of life $(\mathrm{p}=0.032)$. 
Table 1: Patient Characteristics ( $\mathrm{N}=784)$

\begin{tabular}{|c|c|c|c|c|}
\hline Characteristics & Solid Tumors $\mathrm{N}=687$ & $\begin{array}{l}\text { Hematologic Malignancies } \\
\mathrm{N}=97\end{array}$ & p-value & Total $\mathrm{N}=784$ \\
\hline Mean (SD) Age, years & $59.7(14.2)$ & $48.4(18.9)$ & $<0.001 *$ & $58.3(15.3)$ \\
\hline Female, N (\%) & $331(48.2)$ & $30(30.9)$ & $0.001 *$ & $361(46.1)$ \\
\hline Nationality Qatari, N (\%) & $306(44.5)$ & $31(32.0)$ & $0.019 *$ & $337(43.0)$ \\
\hline Primary site, N (\%) & & & $<0.001 *$ & \\
\hline Breast & $112(16.3)$ & 0 & & $112(14.3)$ \\
\hline Lung & $106(15.4)$ & 0 & & $106(13.5)$ \\
\hline Hematology & 0 & $97(100.0)$ & & $97(12.4)$ \\
\hline Brain & $19(2.8)$ & 0 & & $19(2.4)$ \\
\hline Colorectal & $264(38.4)$ & 0 & & $264(33.7)$ \\
\hline Prostate/Bladder & $57(8.3)$ & 0 & & $57(7.3)$ \\
\hline Other & $129(18.8)$ & 0 & & $129(16.5)$ \\
\hline
\end{tabular}

$*$ p-value $<0.05$

Table 2:- Quality of End-of-Life Care Indicators (N=784)

\begin{tabular}{|l|l|l|l|}
\hline Characteristics & Solid Tumors N=687 & $\begin{array}{l}\text { Hematologic Malignancies } \\
\text { N=97 }\end{array}$ & -value \\
\hline Within last 30 days of life & & & \\
\hline Any ER visit & $384(55.9)$ & $66(68.0)$ & $0.024^{*}$ \\
\hline$\geq 2$ ER visits & $114(16.6)$ & $17(17.5)$ & 0.818 \\
\hline Any hospital admission & $542(78.9)$ & $73(75.3)$ & 0.415 \\
\hline$\geq 2$ hospital admissions & $228(33.2)$ & $28(28.9)$ & 0.396 \\
\hline$>14$ days of hospitalization & $189(27.5)$ & $20(20.6)$ & 0.151 \\
\hline ICU admission & $196(28.5)$ & $55(56.7)$ & $<0.001^{*}$ \\
\hline Chemotherapy use & $39(5.7)$ & $11(11.3)$ & $0.033^{*}$ \\
\hline Starting a New Chemotherapy & $26(3.8)$ & $5(5.2)$ & 0.517 \\
\hline Palliative Care Unit Admission & $216(31.4)$ & $9(9.3)$ & $<0.001^{*}$ \\
\hline Hospital Death & $619(90.1)$ & $86(88.7)$ & 0.659 \\
\hline
\end{tabular}

$*$ p-value $<0.05$

Table 3:- Composite Measure of Aggressiveness by Year among the Patients with Hematologic Malignancies

\begin{tabular}{|l|l|l|l|l|l|l|}
\hline & \multicolumn{2}{l|}{ Period of Study } & \multicolumn{2}{l|}{} \\
\hline Variable & $\mathbf{2 0 0 9}$ & $\mathbf{2 0 1 0}$ & $\mathbf{2 0 1 1}$ & $\mathbf{2 0 1 2}$ & $\mathbf{2 0 1 3}$ & $\mathbf{p}$ \\
\hline Proportion of aggressiveness of care (at least one measure) & 88.9 & 79.2 & 75.0 & 75.0 & 50.0 & $0.05^{*}$ \\
\hline $\begin{array}{l}\text { Average No. of aggressiveness of care measures (zero to five } \\
\text { measures maximum) }\end{array}$ & 1.74 & 1.29 & 1.30 & 1.40 & 0.67 & 0.09 \\
\hline
\end{tabular}
$* \mathrm{p}<0.05$

Table 4:- Trends in Measures of the Care Administered Near the End of Life during the 5-Year Study Period among the Patients with Hematologic Malignancies

\begin{tabular}{|l|l|l|l|l|l|l|}
\hline \multicolumn{2}{|l|}{ Period of Study } & \multicolumn{2}{l|}{} \\
\hline Measure of Care & $\mathbf{2 0 0 9}$ & $\mathbf{2 0 1 0}$ & $\mathbf{2 0 1 1}$ & $\mathbf{2 0 1 2}$ & $\mathbf{2 0 1 3}$ & $\mathbf{p}$ \\
\hline $\begin{array}{l}\text { Average No of hospital admissions in the last month of } \\
\text { life }\end{array}$ & 1.22 & 0.92 & 1.15 & 1.10 & 1.17 & 0.718 \\
\hline Average No. of days in the hospital at last encounter & 9.11 & 7.5 & 5.05 & 7.00 & 7.5 & 0.353 \\
\hline Average No. of ICU admissions in the last month of life & 0.70 & 0.54 & 0.70 & 0.60 & 0.33 & 0.267 \\
\hline $\begin{array}{l}\text { Average No. of days spent in the ICU in the last month } \\
\text { of life }\end{array}$ & 2.04 & 2.96 & 2.40 & 3.80 & 0.33 & 0.905 \\
\hline Average No. of ED visits in the last month of life & 0.85 & 1.25 & 1.30 & 0.60 & 0 & $0.032^{*}$ \\
\hline
\end{tabular}

$$
* p<0.05
$$




\section{Discussion:-}

The present study clearly demonstrated that patients with hematologic malignancies are more likely to have more ED visits as well as more ICU admissions in the last month of life compared to those with solid tumors over the same study period from 2009 till 2013 ( $\mathrm{p}=0.001$ and 0.024 respectively). Also, patients with hematologic malignancies in the present study were less likely to be referred to palliative care compared to patients with solid tumors in the last 30 days of life (9\% vs $31 \%$, p <0.001). Those results are in accordance with the recent experience at MD Anderson Cancer Center published by Hui et al in 2014, where it was also shown that patients with hematologic malignancies had significantly more ER visits, ICU admission, tumor-directed therapies and a lack of palliative care involvement compared to patients with solid tumors at end-of-life ${ }^{(\mathbf{1 7})}$.

Those findings are internationally recognized as well through previously published research concerning end of life

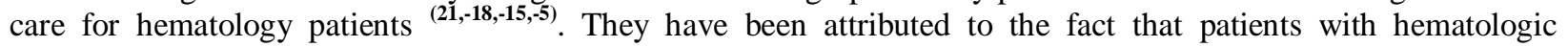
malignancies usually have chemotherapy sensitive tumors compared to patients with solid tumors rendering the use of second or third line salvage therapy a legitimate option for those patients ${ }^{(17,21,18,15)}$. However, one should not overlook the fact that early engagement with palliative care would result in a better quality of life in most of the patients with cancer diagnosis. Those strategies could be integrated in conjunction with any sort of tumor-directed salvage therapies aiming to improve the tolerance of patients to such treatments ${ }^{(23)}$.Despite a statistically significant decline in the overall percentage of aggressiveness along the study period, yet this was not paralleled with an increase in the number of palliative care referrals from the hematologyteam at our center. Referrals from hematology to palliative care at the National Center for Cancer Care \& Research represent only $10 \%$ of all referrals to palliative care during the same period of the present study ${ }^{(2)}$. This relative lack of palliative care involvement in hematologic patients highlights the need to develop programs aiming to improve quality of end-of-life care for patients with hematologic malignancies.

End-of-life is considered nowadays as an important indicator of good quality of care that is well recognized by international oncology associations such as the American Society of Clinical Oncology (ASCO) ${ }^{(24)}$. The previously reported decline in the percentage of aggressiveness of care among solid tumors at our center over the same period of time ${ }^{(3)}$ has been partlyattributed to improved awareness and a higher referral pattern to palliative care along the years from 2009 till 2013. This cannot explain the decline seen in the overall incidence of aggressiveness in the current study as the referral of hematology patients to palliative care did not increase over the same period of time. We believe that the decline of aggressiveness of care in the present study is attributed to the small number of patients included in the study (total of 97 patients) rather than an improvement in the quality of care offered to hematology patients at the end of their life. The use of chemotherapy in the last 2 weeks of life is significantly higher in this group of patients.

In conclusion, the present study clearly demonstrates that patients with hematologic malignancies are less likely to be referred to palliative care compared to patients with solid tumors over the same period of time. They are also having more ER visits as well as more ICU admissions in the last month of their life.

An earlier engagement with palliative care is warranted for patients with hematologic malignancies in our center in order to improve the tolerance of the patients to salvage therapies as well as the quality of their care near end of life.

\section{References:-}

1. Adam H, Hug S, Bosshard G et al: Chemotherapy near the end of life: A retrospective single-centre analysis of patient's charts. BMC Palliative Care 2014, pp 13-26

2. Al-Kindi S.G, Abu Zeinah GF and Hassan A.A: Pattern of hospitalization of patients with cancer in an acute palliative care setting: Qatar's experience. Am J HospPalliat Care 2013: 10: 30 (1), pp 25-28

3. Azza AH, Hassan M, Ayman A, and Pascale H: Trends in the aggressiveness of End-of-life cancer care in the State of Qatar. Journal of Global Oncology, April 2016, pp 68-75

4. Barbera L, Paszat L, Chartier C: Indicators of poor quality end-of-life cancer care in Ontario. Journal of palliative care 2006: 22-1, pp 12-17

5. Barbera L, Taylor C, dudgeon D: Why do patients with cancer visit the emergency department near the end of life? CMAJ 2010: 182 (6), pp 563-568

6. Bousquet A, Malfuson JV, Sanmartin N et al: An 8-year survey of strains identified in blood cultures in a clinical hematology unit. ClinMicrobiol and Infect 2014: vol. 20 (1), pp 7-12 
7. Cooke CR, Feemster LC, Glynn R et al: Aggressiveness of intensive care use among patients with lung cancer in the surveillance, Epidemiology and End Results-Medicare Registry. Chest 2014: 146 (4), pp 916-923

8. Earle CC, Landrum MB, Souza JM, et al: Aggressiveness of cancer care near the end of life: is it a quality-ofcare issue? Journal of Clin. Oncol. 2008: 26, no. 23, pp 3860-3866

9. Earl CC, Neville BA, Landrum MB et al: Trends in the aggressiveness of cancer care near the end of life: Journal of Clin. Oncol. 2004: 22 (2), pp 315-321

10. Earle CC, Nevilla BA, Landrum MB et al: Evaluating claims-based indicators of the intensity of end-of-life cancer care. International Journal for Quality in Health care 2005: Vol. 17 (6), pp 505-509

11. Earle CC, Park ER, Lai B et al: Identifying potential indicators of the quality of end-of-life cancer care from administrative data. Journal of Clin. Oncol. 2003: 21(6), pp 1133-1138

12. Fadul NA, El Osta B, Dalal S et al: Comparison of symptom burden among patients referred to Palliative care with hematologic malignancies versus those with solid tumors. J palliat Med. 2008: 11 93, pp 422-427

13. Franchini M., Frattini F., Crestani S. et al: Bleeding complications in patients with hematologic malignancies. SeminThrombHemost. 2013: 39 (1), pp 94-100

14. HO TH, Barbera L, Saskin R et al: Trends in the Aggressiveness of End-of-life cancer care in the Universal health system of Ontario, Canada - Journal of Clin. Oncol. 2011: 29 (12), pp 1587-1591

15. Howell DA, Roman E, Cox H et al: Destined to die in hospital: Systematic review and meta-analysis of place of death in hematological malignancy. BMC palliative care 2010, 9:9

16. Hui D, El Sayem A, Li Z et al: Antineoplastic therapy use in patients with advanced cancer admitted to an acute palliative care unit at a comprehensive cancer center: a simultaneous care model. Cancer 2010: 116 (8), pp 2036-2043

17. Hui D, Didwaniya N. Vidal M. et al: Quality of End-of-life care in patients with hematologic malignancies: A retrospective cohort study. Cancer 2014: 120 (10), pp 1572-1578

18. Keating NL, Landrum MB, Lamont EB et al: End-of-life care for older cancer patients in the Veterans health administration versus the private sector. Cancer 2010: 116 (115), pp 3732-3739

19. Lee YJ. Yang JH, Le JW et al: Association between the duration of palliative care service and survival in terminal cancer patients. Support Care Cancer 2015: 23, pp 1057-1062

20. Manitta V. Zordan R., Cole-Sinclair M. et al: The symptom burden of patients with hematological malignancy: a cross-sectional observational study. J pain Symptom manage. 2011; 42(3): pp 432-442

21. Mc Grath P, Holewa H: Special considerations for hematology patients in relation to end-of-life care: Australian findings. Eur J Cancer Care 2007: 16 (2), pp 164-171

22. Setogushi S., Earl CC, Glynn R et al: Comparison of prospective indicators of quality of end-of-life cancer care. Journal of Clinical Oncology 2008 : Vol. 26 (35), pp 5671-5678

23. Temel J.S., Greer J.A, Muzikansky A. et al: Early palliative care for patients with metastatic Non-Small Cell lung cancer. N Engl J. Med. 2010: 363, pp 733-742

24. The Quality Oncology practice initiative quality measures 2013 Available from URL: http://gopi.asco.org/program.html. 